\title{
Customer service: management commitment and performance within industrial manufacturing firms
}

\begin{abstract}
The concept of customer service (CS) as applied within manufacturing firms had and will continue to increase in importance. CS is seen as another source of competitive advantage with greater revenue generating potential among manufacturers. However, management commitment to customer service (MCCS) itself is largely noted as a major barrier toward CS success. This study scales firmsôlevel of MCCS and relate it to their performance. From a survey of industrial manufacturing firms operating in the U.K., it was found that Committed firms generally faired well in a number of performance measures as compared to Less Committed firms.
\end{abstract}

Keyword: Customer service; Management commitment; Industrial manufacturing firms 